\title{
Teachers' Perceptions of Students With Special Educational Needs in Two Western Districts of Bhutan
}

\author{
Tshering Womling ${ }^{1}$, Sonam Dhendup ${ }^{1}$, Sherab Jatsho ${ }^{1}$ \\ ${ }^{1}$ Ministry of Education, Thimphu, Bhutan \\ Correspondence: Sonam Dhendup, Ministry of Education, Thimphu, Bhutan.
}

Received: July 23, 2020

Accepted: Nov. 16, 2020

Online Published: Nov. 29, 2020

doi:10.11114/jets.v8i12.5092

URL: https://doi.org/10.11114/jets.v8i12.5092

\begin{abstract}
The present study examined Bhutanese teachers' general perceptions, challenges towards special educational needs (SEN) students, and professional development (PD) and training attended by teachers with their levels of stress. A total of 53 teachers of two SEN schools in western Bhutan participated in this study. The data were collected using the online survey. The findings of this study suggest that although, 55\% of teachers felt that teaching students with or without disabilities together is a good thing, however, one of the challenges certainly was the inadequate numbers of trained and specialised teachers. The findings also indicated that teachers learnt skills in SEN mostly through personal initiatives such a doing further research and reading. Similarly, the results of the study showed that the female teachers were said to have experienced more stress compared to their male counterparts. Further, the study also revealed that some of the challenges identified by teachers while teaching students with SEN were the lack of teacher collaboration within the school, lack of resources, overcrowded classrooms and the lack of professional development and training. Alternatively, the correlation and the prediction analyses further revealed that an estimated of 52\% variability of stress can be predicted by the $\mathrm{PD} /$ trainings attended by the teachers.
\end{abstract}

Keywords: challenges, professional development, special educational needs, stress

\section{Introduction}

Bhutan, like many other developing countries, is committed to developing an inclusive approach to schooling (Schuelka, 2012; Schuelka, 2014; Subba et al., 2018). The claim is validated through the successive five-year policies and plans of the Royal Government of Bhutan (Gross National Happiness Commission, 2019), the Bhutan Education Blueprint (Ministry of Education [MoE], 2014) and the policies of the Ministry of Education (2017). The national standards for inclusive education policy for instance emphasise that "the special educational needs of all students shall be catered to, to enhance both participation in education and the quality of learning" (MoE, 2017, p.4).

The need for inclusive education policy in Bhutan was started in 2002, in the Ninth Five-Year Plan (Royal Government of Bhutan, 2002), hence a Special Education Unit was established under the Department of School Education of the Ministry of Education. The mandate of the SEN office is to look after the needs of both staff and students involved in educating students with SEN and make it inclusive schools (Schuelka\& Johnstone, 2012: Schuelka, 2014).

In the Bhutanese educational context, the term 'special educational needs' (SEN) is used to describe students with a disability (Subba et al., 2018). As of 2019, there are 797 students (492 male and 305 female) enrolled in 19 schools with SEN program (MoE, 2019). As the education system continues to evolve, one of the primary challenges of the modern education system is to support children with different need (Schuelka, 2014; Subba et al., 2018). With more than a decade of experience in implementing SEN program in the selected schools of Bhutan, there are stories of success as well as issues to address.

In the recent times, many studies in SEN have been carried out to investigate the success and challenges of the Bhutanese inclusive educational journey (Chhetri, 2015; Jigyel et al., 2018; MoE 2014; Schuelka, 2014; Schuelka, 2014; Subbha et al., 2018). Still, topics like the professional development (PD) and stress of teachers teaching SEN not so well documented. In the success front, Subba et al. (2018) noted, positive attitude of for the future, satisfaction of the stakeholders, acceptance by the peers, making best use of the available resource, and accommodations and teaching strategies as some avenues to be proud of and carry forward. However, lack of parental support, lack of specialist teaching staff, classroom issues, lack of appropriate resources and facilities, and lack of holistic inclusion were reported 
as not working well in the schools with SEN program. Delving more into the challenges, lack of adequate funds, infrastructure, support services, and expertise to deal with children with SEN (Chhetri, 2015; MoE 2014; Schuelka, 2014; Subbha et al., 2018), professional development for teachers teaching SEN students (Chhetri, 2019), and collaboration between different stakeholders (Jigyel et al., 2018) were recorded. However, given all those challenges, no studies were carried out in the past to see the SEN programs through teachers' lens in Bhutan.

While students with special education needs are included in the general classroom setting, teachers are required to adapt their teaching approaches to meet all students' needs (Byrd \& Alexander, 2020). However, they noted that general teachers are not aware completely as to how to support students with special need. This is in some way a current scenario in Bhutanese schools with SEN program. Thus, the purpose of this paper was to examine Bhutanese teachers' general perceptions, challenges they faced, PD and training attended by teachers and their levels of stress. Therefore, the study aims to assess the teachers' perspective of SEN programs, with special focus on the stress related to teaching SEN students. The following research questions were used to guide this study:

1. What are the teachers' perceptions and challenges while teaching students with special education needs?

2. Is there differences in male and female teachers levels of stress?

3. Is there significant difference in the levels of stress between the demographic variables such as age, qualification, teaching experience and class levels taught?

4. Is there significant relationship between teacher stress and attendance of professional development to teach SEN students?

5. Can teacher's level of stress and anxiety be predicted by professional development course /specialization in SEN education?

H0 5.1: PD attended by teachers have no effect on the levels of teacher stress.

\section{Review of the Related Literature}

Teachers' attitude and perception towards students with special needs have been widely researched (Arrah \& Swain, 2014; Braksiek et al., 2018) area of study. Research has indicated that the attitudes and beliefs of teachers have huge implication in the successful transferral of the SEN program and its contents (Dupourx et al, 2006). Nonetheless, inclusive education in Bhutan is still in its initial stage of implementation and remains to be challenged in certain ways (Jigyel et al., 2018; Schuelka, 2014). Some of the main deterrents were the lack of sufficient budget, infrastructure, support services, professionals to deal with SEN students (Chhetri, 2015; Schuelka, 2014; Subbha et al., 2018), lack of community involvement, and ineffective parent-teacher collaboration (Jigyel et al., 2018; Schuelka, 2014).

The pre-service teachers trained from the two Colleges of Education of Bhutan offers modules on special education but just as an elective module (Subba et al., 2018). Further, "While pre-service teachers gained some knowledge and developed many positive attitudes towards inclusive education, this was insufficient to instil confidence and capacity to ensure inclusive teaching in the classrooms" (Chhetri, 2019, p.11). This in turn can have negative impact towards teacher's quality of interaction with the students and garner stress to the teacher (Byrd \& Alexander, 2020).

Globally, much has been researched on the teacher job stress, as the teaching profession is overwhelmed with high level of stress (Pepe \& Addimando, 2013; Sandilos et al., 2017; Travers, 2017). Further, stress surfaced out to be particularly evident for teachers working in "inclusive settings and special classes within mainstream schools" (Antonion et al., 2009, p.101). The study attributed the additional sources of stress experienced by teachers teaching SEN children to the diverse individual learning requirement and emotional needs of special children.

Due to the challenging students' behaviour, teachers teaching special students as well as general students were found to experience different levels of stress (Kebbi \& Al-Hroub, 2018; Pepe \& Addimando, 2013). Effective PD experiences in the related field were found to increase teachers' self-efficacy and in the identified area of PD (Tschannen-Moran \& McMaster, 2009) which may consecutively mitigate any stress related with that aspect of their profession (Schwarzer \& Hallum, 2008). Comprehensive study was done in the three African countries by Chitiyo et al. (2019) on the need of professional development for special education teachers. They noted that one of the main challenges of the inclusive education in the African countries is the shortage of teachers with all the essential skills to cater to the needs of special child. They suggested that such shortage can be addressed by giving relevant PD to all the teachers dealing with special students.

One of the potential methods to minimize stress for teachers is to provide them with additional skills through PD (Jennings \& Greenberg, 2009). Further, it was noted that the key factor that promotes and influences students' learning outcomes is the continuous professional development programs provided to the teachers (Byrd \& Alexander, 2020; 
Chitiyo et al., 2019; Lee, 2017). In order to fill in the void left-out during the teacher training program and to let teachers grow professionally, MoE has initiated Professional Development (PD) programs at different levels for teachers in Bhutan. Correspondingly, In-Service Education of Teachers (INSET) Master Plan and Bhutan Education Blueprint (2014) supports that continuous professional development and other resources are required for successful implementation of the curriculum (MoE, 2012, 2014). However, lack of professional development opportunities for teachers teaching in the schools with SEN program was recorded (Chhetri, 2015).

While it was observed that the psychological needs of teachers have no variation with respect to gender, female teachers were significantly higher in perceived stress level compared to male teachers (Avci et al., 2017). Similar findings were also reported by Antonion et al. (2009) when 'responsibility for pupils' and 'pressure of time at school' were taken as important source of stress. For different age groups, the sample with age range 41-50 showed more stress than both younger and older age groups SEN programs (Antonion et al., 2009).

Conversely, no study was ever carried out to understand the stress level and professional development requirement for teachers of inclusive schools in Bhutan. The study attempted to fill the literature gap and contribute some light on the stress felt by teachers to deal with special students.

\section{Methods}

This study uses a cross sectional survey design. A single stage simple random sampling technique was employed. The self-reported survey was sent to 101 teachers in two schools that catered to SEN schools. Only 53 teachers completed and responded to the survey. School A has 62 SEN while 16 SEN were recorded for school A. The participants of the study were teachers of two SEN schools in Western Bhutan. School A had 73 teachers while school B had 28 teachers. These two schools are schools with SEN programme identified by the ministry of education, Bhutan.

\section{Instrumentation}

The survey questionnaire had four parts. Part A gathered personal information of the participants. This included: (a) gender, (b) teaching experience, (c) age, (d) level of education. Part B (6 items) that examined the "General Perceptions of Inclusion of Secondary School Teachers" and part D of the questionnaire "Challenges of Teaching Students with Special Education Needs" (5 items) were adapted from the (Arrah \& Swain, 2014) study, "Teachers' perceptions of students with special education needs in Cameroon secondary schools." The part C of the questionnaire was adapted and modified from (Schutz \& Long, 1988) study, although this revised version had 36 items, only (5 items) related to teacher stress was used for this current study. A four-point Likert rating scale (Strongly Agree=1, Agree= 2, Disagree= 3, Strongly Disagree $=4$ ) was used for all parts of the survey expect for part A. Also, the desk data for PD attendance in 2019 (SEN) were collected from both the schools.

\section{Data collection}

The internet survey method was found to be the most suitable means of data collection as there were restrictions of movement posed by the COVID-19 pandemic. The greatest advantage was the ease of circulation and greater reach. The survey link was sent to all the teachers $(\mathrm{N}=101)$ through the help of school principals and teachers in these two SEN schools in Western Bhutan. Generally, in Bhutan, often than not, online response rate is relatively low compared to paper-based survey administration.

\section{Data analysis}

The data collected were subjected to descriptive as well as the inferential statistics. A simple linear regression analysis was used to predict teachers' stress from their professional development training received within the last three years.

\section{Results}

\section{General Perceptions and challenges while teaching students with special education needs.}

It can be seen in Table 1 that the $43 \%(M=1.72 ; S D=0.63)$ of teachers have some knowledge about teaching SEN students and 55\% of teachers feel that teaching students with or without disabilities together is a good thing. It also indicated that teachers learnt skills in SEN mostly doing self-reading (59\%). 
Table 1. General perceptions of teachers towards SEN

\begin{tabular}{lccc}
\hline & M & SD & $\%$ \\
\hline I have knowledge about students with SEN & 1.72 & 0.63 & 43.0 \\
I am prepared to teach all types of students & 2.09 & 0.74 & 52.3 \\
I have read about teaching students with SEN & 1.98 & 0.72 & 49.5 \\
I have skills for teaching SEN & 2.34 & 0.75 & 58.5 \\
I adapt my lessons to meet the unique need of students with & 2.09 & 0.59 & 52.3 \\
SEN & & & \\
It's good to teach students with/without disabilities together & 2.19 & 0.78 & 54.8 \\
\hline
\end{tabular}

Some of the challenges faced by teachers while teaching students with SEN is presented in Table 2. A lack of teacher collaboration, $(M=1.83 ; S D=0.58)$; lack of resources $(M=1.71 ; S D=0.60)$; overcrowded classrooms $(M=1.58 ; S D=$ $0.71)$ and lack of professional development and training $(M=1.58 ; S D=0.71)$ were cited as some of the challenges related to teaching students with SEN.

Table 2. Challenges faced by teachers while teaching students with SEN

\begin{tabular}{lccc}
\hline & M & SD & $\%$ \\
\hline Teachers collaborate to help students with SEN & 1.83 & 0.58 & 45.75 \\
There is support from the principal to teach students with SEN & 2.32 & 0.72 & 58 \\
There are sufficient resources in the school to teach students & 1.71 & 0.60 & 43 \\
with SEN & & & \\
School has a system to detect and help students with SEN & 2.31 & 0.72 & 58 \\
I took a course/workshop in Special Education & 1.58 & 0.71 & 39.5 \\
\hline
\end{tabular}

\section{Differences in male and female teachers' levels of stress}

An independent-samples t-test was run to determine if there were differences in stress between male and female teachers while teaching SEN students is presented in Table 3. The female teachers were said to have experienced more stress $(1.62 \pm 0.50)$ than male teachers $(1.44 \pm 0.51)$, however, the differences of $0.22(95 \% C I,-.22$ to .34$), t(51)=$ $2.365, p=0.22$ were not statistically significant.

Table 3. Differences in stress between male and female teachers

\begin{tabular}{llccccccc}
\hline & Gender & $N$ & $M$ & $S D$ & $S E M$ & $t$ & $d f$ & $p$ \\
\hline \multirow{2}{*}{ Stress } & male & 27 & 1.44 & 0.51 & 0.10 & -1.24 & 51.00 & 0.22 \\
& female & 26 & 1.62 & 0.50 & 0.10 & & & \\
\hline
\end{tabular}

\section{Difference in the levels of stress between the demographic variables such as age, qualification, teaching experience and class levels taught.}

A one-way ANOVA was conducted to determine if the teacher demographic variables exhibited difference in the way teachers perceive teaching SEN students as stressful as shown in Table 4. There were no observable statistically significant differences to stress by teachers age, qualification, levels taught. However, a statistically significant differences were observed in teaching experiences $(p=.001)$. Tukey post hoc analysis revealed that teachers with 16 years and more had experienced higher levels of stress $(p=.046)$ as compared to other groups of teachers. 
Table 4. ANOVA results based on demographic variables

\begin{tabular}{|c|c|c|c|c|c|c|c|c|c|}
\hline Demographics & & $N$ & $M$ & $S D$ & ANOVA & $d f$ & $f$ & $p$ & Post Hoc \\
\hline \multirow[t]{3}{*}{ Age } & $20-30$ & 13 & 2.77 & 0.725 & Between Groups & 2 & 1.466 & 0.241 & \\
\hline & $31-40$ & 23 & 2.35 & 0.832 & Within Groups & 50 & & & \\
\hline & $41-50$ & 17 & 2.65 & 0.702 & & & & & \\
\hline \multirow[t]{7}{*}{ Qualification } & PTC & 3 & 2.67 & 0.577 & Between Groups & 6 & 0.656 & 0.686 & \\
\hline & B.Ed (P) & 26 & 2.65 & 0.745 & Within Groups & 46 & & & \\
\hline & B.Ed (S) & 6 & 2.5 & 0.837 & & & & & \\
\hline & B.Ed (Dzo) & 4 & 2 & 0 & & & & & \\
\hline & PGDE & 5 & 2.6 & 1.14 & & & & & \\
\hline & Masters & 7 & 2.29 & 0.756 & & & & & \\
\hline & Others & 2 & 3 & 1.414 & & & & & \\
\hline \multirow[t]{4}{*}{ Teaching Experience } & below 5 & 9 & 3.11 & 0.782 & Between Groups & 3 & 2.469 & $0.001^{*}$ & \\
\hline & $6-10$ & 9 & 2.56 & 0.882 & Within Groups & 49 & & & \\
\hline & $11-15$ & 15 & 2.27 & 0.704 & & & & & \\
\hline & 16 and above & 20 & 2.5 & 0.688 & & & & & 0.046 \\
\hline \multirow[t]{4}{*}{ Teaching Levels } & PP-III & 20 & 2.65 & 0.745 & Between Groups & 3 & 0.769 & 0.517 & \\
\hline & IV-VI & 14 & 2.5 & 0.76 & Within Groups & 49 & & & \\
\hline & VII \& VIII & 11 & 2.27 & 0.905 & & & & & \\
\hline & IX \& X & 8 & 2.75 & 0.707 & & & & & \\
\hline
\end{tabular}

*Note: PTC=Primary Teaching certificate; B.Ed (P)=Primary; B.Ed (S)=Secondary; B.Ed (Dzo)= National language teacher; PGDE= Post-graduate Diploma in Teaching; Others= General degrees like Psychology.

\section{Relationship between teacher stress and attendance of professional development}

The Pearson product-moment correlation was used to determine the relationship between the PD and the levels of stress (see Table 5). Preliminary analyses showed the relationship to be linear with both the variables normally distributed, as assessed by Shapiro-Wilk's test $(p>.05)$ and there were no outliers. There was a statistically significantly, strong negative between those teachers who attended $\mathrm{PD} /$ trainings and stress, $r(51)=-.72, p<.005$, with $\mathrm{PD} /$ training explaining $52 \%$ of the variation in teacher stress.

Table 5. Correlations statistics between the PD and Stress

\begin{tabular}{lccc}
\hline & & PD & Stress \\
\hline PD & $\mathrm{r}$ & - & $-.72^{* *}$ \\
Stress & $\mathrm{r}$ & $-.72^{* *}$ & - \\
\hline
\end{tabular}

**. Correlation is significant at the 0.01 level (2-tailed).

\section{Level of stress and anxiety predicted by professional development course /specialisation in SEN education}

A simple linear regression was conducted to understand the effect of PD/ specialized course in dealing with SEN established that attendance in such programmes could statistically significantly predict level of teacher stress, $F(1,51)$ $=57.25, p<.001, R^{2}=0.529$ (presented in Table 6) and teacher attendance in professional development related to SEN accounted for $52.9 \%$ (given in Table 6 and Table 7) of the explained variability in teacher stress. The regression equation was, predicted stress $=2.556+-0.77 \times$ (PD attended). Further, the regression coefficients and standard errors presented in Table 8 indicate that $\mathrm{PD} /$ training was found to be statistically significant predictor to the prediction (Stress), $p<.05$.

Thus, the regression model can be expressed as follows: 


$$
\text { Stress }=b 0+(b 1 x \text { Attended } P D / \text { training })
$$

Table 6. Regression Model Summary

\begin{tabular}{lllllll}
\hline Model & $\mathrm{R}$ & $\mathrm{R}$ Square & $\begin{array}{l}\text { Adjusted } \\
\text { Square }\end{array}$ & $\mathrm{R}$ & $\begin{array}{l}\text { Std. Error of the } \\
\text { Estimate }\end{array}$ & Durbin-Watson \\
\hline 1 & $.727^{\mathrm{a}}$ & .529 & .520 & .349 & 2.06 \\
\hline
\end{tabular}

a. Predictors: (Constant), PD1

b. Dependent Variable: Stress

Table 7. ANOVA Results

\begin{tabular}{lllllll}
\hline Model & & SEM & df & Mean Square & F & Sig. \\
\hline 1 & Regression & 6.98 & 1 & 6.98 & 57.25 & $.000^{\mathrm{b}}$ \\
& Residual & 6.22 & 51 & .122 & & \\
& Total & 13.20 & 52 & & & \\
\hline
\end{tabular}

a. Dependent Variable: Stress

b. Predictors: (Constant), PD

Table 8. Multiple Regression Coefficients

\begin{tabular}{llllllll}
\hline \multicolumn{7}{c}{} & \multicolumn{2}{l}{$\begin{array}{l}\text { Unstandardized } \\
\text { Coefficients }\end{array}$} & $\begin{array}{l}\text { Standardized } \\
\text { Coefficients }\end{array}$ & & & & \\
\hline Model & $B$ & $S E$ & Beta & $t$ & Sig. & ZO & VIF \\
\hline 1 (Constant) & 2.556 & 0.14 & & 17.74 & 0.000 & -0.72 & 1 \\
Attended PD/Training & -0.77 & 0.1 & -0.72 & -7.56 & 0.000 & & \\
\hline
\end{tabular}

a. Dependent Variable: Stress

\section{Findings on Null hypothesis}

HO 5.1: PD attended by teachers have no effect on the levels of teacher stress.

The predicted null hypothesis was rejected because as there was statistically significant relationship between the PD attended by teachers and the levels of teacher stress $[\beta=-0.72>.001]$ (see Table 9).

\section{Discussion}

The findings from this study suggest that out of 53 teacher respondents more than $40 \%$ got a professional development workshop related to teaching SEN students. Although, 55\% of teachers felt that teaching students with or without disabilities together is a good thing, however, the lack of professional development and further training can thus be a contributing factor why teachers feel stress while teaching students with SEN in these two identified schools. The findings also indicated that teachers learnt skills in SEN mostly through personal initiatives such a doing further research and reading. While the study also revealed that some of the challenges faced by teachers while teaching students with SEN are the lack of teacher collaboration within the school, lack of resources, overcrowded classrooms and the lack of professional development and training, which were similarly found in studies by (Chhetri, 2015; Schuelka, 2014; Subbha et al., 2018).

Similarly, the findings of the study seemed to show that the female teachers were said to have experienced more stress compared to male teachers. The finding was in parallel to (Antonion et al., 2009; Avci et al., 2017) study which also showed that female teachers exhibited higher level of stress. Nonetheless, in this study, there was no evidence of statistically significant differences between the male and female teachers. The female teachers experiencing more stress perhaps could be explained due to the challenging students' behaviour (Kebbi \& Al-Hroub, 2018; Pepe \& Addimando, 2013). Nevertheless, differences between teacher demographic variables, the differences in stress between these variables such as teacher age, qualification, levels taught were found to have evidence of statistical differences. A statistically significant differences were observed in teaching experiences where teachers with 16 years and more, had experienced higher levels of stress compared to other groups of teachers. The existence of such differences is not surprising as number of years increases the level of interest in teaching particularly SEN students could be shifting, showing a decreasing interest and exhibiting increased stress (Antonion et al., 2009). 
Besides, the results of predictive analysis tended to show a strong negative relationship between the PD and teacher stress. Further, the correlation and the prediction analyses revealed that an estimated of $52 \%$ variability of stress can be predicted by the $\mathrm{PD} /$ trainings attended by the teachers.

\section{Conclusion}

This study made an attempt to examine teachers' perceptions, challenges, and attendance of $\mathrm{PD} /$ training in predicting the stress of teachers in two SEN schools in Bhutan.

Overall, this present study concludes that although teachers in these schools perceive SEN students positively given the challenges that they faced while teaching students with SEN. Also, the levels of teacher stress could be related to attendance of PD and trainings related to SEN must be planned in order to reinvigorate and uplift teacher morale and their self-efficacy.

\section{Limitation}

This study had its own limitations. Firstly, the sources of teacher stress, and strategies related to coping stress among the secondary school teachers have not been studied. Other limiting factors include the use of only quantitative data; however, future studies could employ mixed methods study to include interview techniques to gain better understanding and insights from the SEN school administrators, SEN co-ordinators, SEN team members, and also may include general teachers who teach SEN students. This current study could not study some of the important components of inclusive education in Bhutan. Thus, future studies could therefore explore the magnitude of the student disability, inclusive school culture, values, standards, school climate, student recruitment process (admission), leadership and management, planning and budgeting for inclusive education, individual education plans by teachers and administrators, and finally teaching and learning.

\section{References}

Antonion, A. S., Polychroni, F., \& Kotroni, C. (2009). Working with students with special educational needs in Greece: teachers' stressors and coping strategies. International Journal of Special Education, 24(1), 100-111.

Arrah, R. O., \& Swain, K. D. (2014). Teachers' perceptions of students with special education needs in Cameroon secondary schools. International Journal of Special Education, 29(3), 101-110.

Avci, A., Bozgeyikli, H., \& Kesici, S. (2017). Psychological needs as the predictor of teachers' perceived stress levels. Journal of Education and Training Studies, 5(4), 154-164. https://doi.org/10.11114/jets.v5i4.2274

Braksiek, M., Groben, B., Rischke, A., \& Heim, C. (2018). Teachers' attitude toward inclusive physical education and factors that influence it. German Journal of Exercise and Sport Research. https://doi.org/10.1007/s12662-018-0546-8

Byrd, D. R., \& Alexander, M. (2020). Investigating special education teachers'knowledge and skills: preparing general teacher preparation for professional development. Journal of Pedagogical Research, 4(2). https://doi.org/10.33902/JPR.2020059790

Chhetri, K. K. (2015). Investigating teachers' concerns and experiences in teaching children with special educational needs in Bhutan. PhD diss, Queensland University of Technology

Chitiyo, M., Hughes, E. M., Chitiyo, G., Changara, D. M., Itimu-Phiri, A., Haihambo, C., ... Dzenga, C. G. (2019). Exploring teachers' special and inclusive education professional development needs in Malawi, Namibia, and Zimbabwe. International Journal of Whole Schooling, 15(1), 28-49.

Dupoux, E., Hammond, H., Ingalls, L., \& Wolman, C. (2006). Teachers' attitudes towards students with disabilities in Haiti. International Journal of Special Education, 21(3), 1-13.

Gross National Happiness Commission. (2019). Twelfth five-year plan, 2018-2023. Royal Government of Bhutan.

Jennings, P. A., \& Greenberg, M. T. (2009). The prosocial classroom: Teacher socialand emotional competence in relation to student and classroom outcomes. Review of Educational Research, 79, 491-525. https://doi.org/10.3102/0034654308325693

Jigyel, K., Miller, J. A., Mavropoulou, S., \& Berman, J. (2018). Parental communication and collaboration in schools with special needs (SEN) programmes in Bhutan. International Journal of Inclusive Education. https://doi.org/10.1080/13603116.2018.1426053

Kenni, M., \& Al-Hroub, A. (2018). Stress and coping strategies used by special education and general classroom teachers. International Journal of Special Education, 33(1), 34-61.

Lee, S. K. (2017). Singapore's education system: Some key success factors. New Zealand Centre for Political Research. 
Ministry of Education. (2001). Bhutan Education Sector Strategy: Realizing Vision 2020. Royal Government of Bhutan.

Ministry of Education. (2012). In-service education of Teachers (INSET) in Bhutan: Master Plan.

Ministry of Education. (2014). Bhutan Education Blueprint 2014-2024: Rethinking Education. Royal Government of Bhutan.

Ministry of Education. (2017). Standards for Inclusive Education. ECCD \& SEN Division.

Ministry of Education. (2019). Annual education statistic 2019. Policy and Planning Division, MoE

Pepe, A., \& Addimando, L. (2013). Comparison of occupational stress in response to challenging behaviors between general and special education primary teachers in northern Italy. International Journal of Special Education, 28(1), 14-26.

Royal Government of Bhutan. (2002). "Ninth Five-Year Plan.” http://www.gnhc.gov.bt/

Sandilos, L. E., Goble, P., Rimm-Kaufman, S., \& Pianta, R. C. (2017). Does professional development reduce the influence of teacher stress on teacher-child interactions in pre-kindergarten classrooms? Early Childhood Research Quarterly, 42, 280-290. https://doi.org/10.1016/j.ecresq.2017.10.009

Schuelka, M. J. (2014). Constructing disability in Bhutan: schools, structures, policies, and global discourses. PhD diss., University of Minnesota.

Schuelka, M. J., \& Johnstone, C. (2012). Global trends in meeting the educational rights of children with disabilities: from international institutions to local responses. Reconsidering Development 2(2), Article 3.

Schutz, R. W., \& Long, B. C. (1988). Confirmatory factor analysis, validation and revision of a teacher stress inventory. Educational and Psychological Measurement, 48, 497-511. https://doi.org/10.1177/0013164488482025

Schwarzer, R., \& Hallum, S. (2008). Perceived teacher self-efficacy as a predictor ofjob stress and burnout: Mediation analyses. Applied Psychology, 57, 152-171. https://doi.org/10.1111/j.1464-0597.2008.00359.x

Subba, A. B., Yangzom, C., Dorji, K., Choden, S., Namgay, U., Carrington, S., \& Nickerson, J. (2018). Supporting students with disability in schools in Bhutan: perspectives from school principals. International Journal of Inclusive Education. https://doi.org/10.1080/13603116.2018.1514744

Travers, C. (2017). 'Current knowledge on the nature, prevalence, sources and potential impact of teacher stress' in. McIntyre, T.M. et al. (eds.), Educator Stress. https://doi.org/10.1007/978-3-319-53053-6_2

Tschannen-Moran, M., \& McMaster, P. (2009). Sources of self-efficacy: Four professional development formats and their relationship to self-efficacy and implementation of a new teaching strategy. The Elementary School Journal, 110, 228-245. https://doi.org/10.1086/605771

\section{Copyrights}

Copyright for this article is retained by the author(s), with first publication rights granted to the journal.

This is an open-access article distributed under the terms and conditions of the Creative Commons Attribution license which permits unrestricted use, distribution, and reproduction in any medium, provided the original work is properly cited. 